\title{
ROSARIO PI: UNA NARRADORA PIONERA E INVISIBILIZADA
}

\author{
Olvido Andújar Molina \\ Facultad de Ciencias Sociales y de la Educación \\ Universidad Camilo José Cela
}

http://dx.doi.org/10.5209/rev_NOMA.2014.v43.n3.49287

\begin{abstract}
Resumen.- Rosario Pi Brujas (Barcelona, 1899 - Madrid, 1967) fue una de las pioneras de la Cinematografía española. Su huella en este arte puede definirse, sin ningún lugar a dudas, como polifacética y valiente. Llegó al cine de la mano del mexicano Emilio Gutiérrez Bringas y del español Pedro Ladrón de Guevara, con quienes fundó la productora Star Films, responsable de films como Yo quiero que me lleven a Hollywood, Edgar Neville, 1931 y El hombre que se reía del amor, Benito Perojo, 1932. Rosario Pi también se adentró en el mundo de la escritura de guión en películas como Doce hombres y una mujer, dirigida por Fernando Delgado en 1934 y El gato montés, película que ella misma dirigiría en 1935.
\end{abstract}

Junto a Helena Cortesina, figura como una de las pioneras del cine hecho por mujeres en España. Con el estallido de la guerra civil, ambas mujeres habrían de convertirse en exiliadas primero y en invisibles después. Rosario Pi tuvo que huir con su actriz María Mercader a París, desde donde pasaron a Italia.

Fue una narradora adelantada a su tiempo, introduciendo en el cine español arquetipos femeninos autosuficientes y liberados en el terreno de la sexualidad. Además, presentaba y desaprobaba la violencia machista, denuncia que aún tardaría décadas en instaurarse en la cinematografía de nuestro país.

Pese a todo, la cineasta fue rechazada por el ambiente intelectual de la Segunda República Española, al ser acusada de fascista. Más tarde, sería ignorada por el régimen franquista, que no aceptaría a una mujer cineasta y mucho menos vanguardista. Rosario $\mathrm{Pi}$, que regresó a España durante la posguerra, no pudo volver a rodar cine. Su último trabajo fue la dirección de un restaurante.

Palabras clave.- Segunda República Española, pionera, mujer, cineasta, narradora, guionista, artista invisibilizada

Abstract.- Rosario Pi Brujas (Barcelona, 1899 - Madrid, 1967) was one of the pioneers of Spanish Film. Her mark in Spanish Cinema can be defined as versatile and stout. She came to the film industry from the hand of the Mexican director Emilio Gutiérrez Bringas and the Spanish director Pedro Ladrón de Guevara, with whom she founded the Production Company Star Film, producer of films as Take me to Hollywood directed by Edgar Neville in 1931, and The man who laughed of love directed by Benito Perojo in 1932. Rosario Pi also was a scriptwriter of films like Twelve men and a woman directed by Fernando Delgado in 1934, and of The Wildcat directed by herself in 1935 .

Along with Helena Cortesina, both of them are pioneers of Spanish films made by women. With the outbreak of civil war, they would become exiled women at first and unseen artists in the end. Rosario Pi fled with the actress María Mercader to Paris. Later, they relocated to Italy.

She was a storyteller ahead of her time, introducing to Spanish cinema feminine archetypes who were both independent and sexually liberated. She also presented and condemned male violence, a complaint that would take decades to be established within filmmaking in our country.

In spite of this, the filmmaker was rejected during the Second Spanish Republic because she was accused of being a fascist. Later, she was disregarded by the Franco regime, who would not accept a filmmaker, never mind a pioneer, who was a woman. Rosario Pi returned to Spain during the postwar period, but she never made films again. Her last job was running a 
restaurant.

Keywords.- Spanish Second Republic, Pioneer, woman, filmmaker, storyteller, screenwriter, unseen artist

\section{Introducción: el acceso de las mujeres a los espacios públicos durante la Segunda República}

Es una realidad sobradamente conocida que es desde los primeros años del siglo XX cuando Europa empieza a observar cómo la mujer accede, por primera vez, a esferas de la vida pública que hasta entonces le habían sido negadas. A partir de la Primera Guerra Mundial, las demandas del movimiento feminista empiezan a recoger unos frutos antes inimaginados, en parte debido a la incorporación de la mujer a los puestos de trabajo que los hombres, en el frente, dejaban libres. Esta nueva realidad repercutió irremediablemente en una nueva valorización y reconocimiento de la mujer en el ámbito laboral, "superando el prejuicio difundido durante el siglo anterior, de que el trabajo realizado por mujeres era un trabajo poco cualificado pues hasta ellas podían ejercerlo" (San Felipe, 65).

La nueva valorización de la mujer venía dada no solo por su incorporación al trabajo, sino también por la consecución paulatina del sufragio femenino desde los primeros años del siglo XX. En este sentido, cabe recordar que Finlandia sería el primer país europeo en aprobar el voto de la mujer en 1906, a quien seguiría Noruega en 1913. Un poco más tarde, en 1918, accedían al voto las mujeres inglesas mayores de 30 años y en 1928 lo harían las mayores de 21 años (Monterde, p. 265). Ya en 1931 se unían las portuguesas y las españolas. En nuestro país, el sufragio femenino fue recogido por la Constitución de la Segunda República, si bien, con la instauración de la dictadura franquista, se prohibieron las elecciones libres y con ello cualquier tipo de sufragio, desandando el camino de logros en pro de los derechos y libertades obtenidos hasta entonces.

Es también en estos momentos cuando se produce una mejora en la educación y un mayor acceso de la mujer a la escolarización. No obstante los orígenes de los colegios femeninos en España se encontraban un siglo y medio antes de la Segunda República. Había que remontarse hasta 1783, durante el reinado de Carlos III, para encontrar escuelas para niñas en nuestro territorio. Ahora bien, la formación impartida en estos centros

era distinta para los niños que para las niñas. Mientras a los primeros se les enseñaba a leer, escribir y contar y Gramática... además de los rezos y el catecismo, a las niñas se les enseñaba tan sólo rezos y 
labores, desde las más sencillas, como la faja y la calceta, hasta las más difíciles, como los encajes y bordados (Anderson y Zinsser, 613).

Una centuria después, en los últimos años del siglo XIX, el $71 \%$ de las españolas seguían atrapadas en una situación de analfabetismo, siendo muy pocas las que sabían leer y escribir, y hasta 1910 no pudieron matricularse libremente en estudios universitarios, ya que necesitaban un permiso de las autoridades (Monterde, 265).

Las mujeres de nuestro país tendrían que esperar hasta los primeros gobiernos de la Segunda República para ver una reforma profunda del sistema educativo que incluía, entre muchas otras medidas, la puesta en marcha de un sistema coeducativo. Con esto se experimentó un notable incremento del alumnado femenino desde el curso escolar de 1932/1933 en adelante -con respecto a los años anteriores a la república-, tanto en la escuela primaria como en la enseñanza media, la enseñanza profesional y la superior (Folguera, pp. 499501).

Este clima especial de la Segunda República, preocupada por la culturización de la sociedad en general y de la mujer en particular, propicia que la mujer pase, por primera vez en España, a un primer plano de la esfera pública. Así es como aparecen figuras tan célebres y reconocidas como Victoria Kent, María Zambrano, Dolores Ibarruri, Zenobia Camprubí, Clara Campoamor o Margarita Xirgú, entre otras. No solo ellas, también surgieron otras muchas voces, tal vez menos conocidas y recordadas, como la oftalmóloga y atleta Aurora Villa, pionera por partida doble: en el ejercicio de la medicina y en sus logros deportistas, destacando en el esquí, la natación, el baloncesto, el piragüismo y el atletismo. En 1932 obtuvo tres medallas en Barcelona: en salto de altura, lanzamiento de jabalina y en la prueba de atletismo de 600 metros (Ontañón). También la periodista y traductora Marina Ginesta, convertida en icono de la Guerra Civil cuando Hans Gutmann la fotografió vestida de miliciana en la terraza del Hotel Colón de Barcelona. Tenía solo 17 años cuando posó para el fotógrafo alemán y ejerció, durante la guerra, como periodista, mecanógrafa e intérprete del corresponsal del diario soviético Pravda (Antón). Las pintoras surrealistas Maruja Mallo -transgresora como pocas y miembro del Grupo del 27-, Remedios Varo o Ángeles Santos, y escritoras como Carmen Conde o María Teresa León, se sumarían a este grupo de mujeres protagonistas del ambiente cultural republicano.

\section{Las mujeres como narradoras y literatas}

Si bien en el mundo de la narración de historias, son los nombres de autores hombres los que tradicionalmente han sobrevivido al paso del tiempo quedando recogidos por la Historia de este arte, no es menos cierto que las mujeres han dejado también su huella y su voz desde los inicios de la literatura, aunque casi siempre de una forma anecdótica. Tal es el caso de las escritoras en la Edad 
Media, época en la, aunque nos cuesta encontrar plumas femeninas, sobresalen los nombres de Eloísa, autora de unas apasionadas cartas dirigidas a su amado Abelardo; la mística Hildegard von Bingen; la trovadora María de Ventardorn; la narradora María de Francia; la poeta y prosista Cristina de Pizán; y Leonor López de Córdoba, una de las primeras autoras en castellano de quien se conserva un texto autobiográfico (Cabanes). En este periodo cabe destacar, sobre todo, a Mayor Arias, María Sarmiento, Isabel González y Florencia Pinar (Pérez Priego, pp. 55-66). No obstante, e iniciado ya el Renacimiento en el siglo XVI, la literatura creada por mujeres dejó de ser una rareza (Von Der Walde y Reinoso). Así encontramos plumas como las de Catalina de Paz, Catalina de Zúñiga, Francisca de Aragón, Isabel Mexía, Andrea de Mendoza e Isabel de Vega. También, claro está, sobresalen los escritos de Santa Teresa de Jesús, Isabel de Liaño, Ana de Castro y Egas, Eugenia Buesso, Oliva Sabuco, y María de Zayas entre otras.

Dicho de otro modo, no podemos obviar que la Historia de la literatura española se ha escrito también con pluma femenina. Por ello no es de extrañar que, al llegar el siglo XX, surgieran multitud de narradoras dispuestas a defender su papel en este arte. Si Emilia Pardo Bazán ya había demostrado desde el siglo anterior que la mujer tenía toda la legitimidad para incursionar en las letras, con la llegada de la Segunda República surgen numerosos nombres de literatas que reclaman un espacio donde alzar su voz. Es el caso de Federica Montseny, quien antes de convertirse en la primera Ministra de la Historia de España, había firmado multitud de artículos en prensa y varias novelas.

El ejemplo de Montseny no fue aislado. Una gran cantidad de narradoras eclosionaron en este tiempo y este ambiente que les era, sin duda, aliado y propicio. Entre muchas otras, pueden destacarse los nombres de Carmen Conde, María Goyri, Zenobia Camprubí, María Teresa León, Margarita Nelken, Isabel Palencia de Oyarzabal, Cecilia de Guilarte, Irene Falcón, Silvia Mistral, Magdalena Martínez Carreño María José Chopieta, María Luisa Elío y Luisa Carnés -escritora autodidacta de familia humilde quien, en 1930, publicó Natacha, su primera novela. En 1936 estrenó su primera obra de teatro en un programa que incluía a Rafael Alberti y a Irene Falcón si bien, como muchas otras, hubo de exiliarse. La muerte le sorprendió a los 59 años en un accidente de tráfico en México y en los años sesenta, lo que la llevó a una invisibilidad absoluta en una España con una dictadura que negaba a sus intelectuales de izquierdas y en la que todavía no había surgido una preocupación seria por recuperar la memoria histórica del país (Plaza).

\section{Las mujeres en la narración cinematográfica de la Segunda República}

En esta línea de creadoras menos recordadas e invisibles se sitúan también las narradoras audiovisuales, aquellas que contaron historias a través de la cinematografía y, de manera más concreta, quien nos ocupa en esta investigación y quien ha sido sorprendentemente olvidada -aun más, invisibilizada-: Rosario Pi, guionista, productora y directora de cine. Acusada 
de filofascista por el círculo intelectual republicano, fue asimismo negada por el franquismo, con total seguridad por ser vanguardista y mujer ocupando una profesión tradicionalmente masculina. Más tarde, fue también ignorada por quienes se encargaron de la recuperación de la memoria histórica de nuestro país, al haber sido en teoría simpatizante del alzamiento militar más dramático de la historia de España.

Rosario Pi se integró en un cine coincidente con la llegada e instauración del sonoro. No solo esto, sino también con la realización de un cine popular que perseguía casi con exclusividad unos objetivos meramente comerciales. Es en este contexto en el que surgen, entre otros, los nombres de los reconocidos Florián Rey, Benito Perojo, Luis Buñuel, Luis Marquina y José Luis Sáenz de Heredia. Nombres que respondían, casi siempre, a artistas hombres. Cabe preguntarse por qué la mujer, que cómo hemos apuntado, está ocupando en estos años una esfera pública y, podríamos aventurarnos a decir que también jugando un papel primordial en ámbitos tan dispares como la política, la educación y la literatura, sin embargo, no encuentra un hueco de importancia en el cine. Al menos, no está en papeles de responsabilidad. Son anecdóticas las experiencias de dirección, producción o guión. Tanto es así que, hasta los años noventa, solo se contaban los nombres de once mujeres directoras en la cinematografía española (Zecchi, p. 315).

En el cine, la mujer sigue apareciendo delante de la cámara. Como sabemos, son multitud de actrices las que destacan en estos años. Las estrellas más populares de la época tal vez sean Estrellita Castro, Imperio Argentina y Carmen Amaya. Pero también Antonia -Antoñita- Colomé, Catalina Bárcena, Rosa -Rosita- Díaz de Gimeno y Margarita Xirgú, a la que ya nos hemos referido y a la que conocemos sobradamente por ser la musa de Federico García Lorca. Xirgú, como muchas de estas mujeres, como Colomé, Bárcena y Díaz de Gimeno, también hubo de conocer el exilio ya hasta su muerte, falleciendo en Montevideo el 25 de abril de 1969.

Sin embargo, al margen de la aportación de las actrices, cuesta, y mucho, encontrar mujeres en otra esfera de la cinematografía. Tan solo destacan un par de nombres de mujeres que dirigieron cine antes o durante la Segunda República española. La primera de ellas es Helena Cortesina, quien produce y dirige en 1922 Flor de España o la leyenda de un torero. Cortesina, que había nacido en Valencia en 1904, también tendría que exiliarse y moriría en Buenos Aires en 1984. Bailarina primero y actriz después, no consiguió hacerse con el prestigio de ser considerada la primera mujer directora del cine español, al ser su responsabilidad en esta labor meramente casual. Al parecer,

dirigió "Flor de España o la leyenda de un torero" porque un cura llamado José María Martín López, cuyo pseudónimo fue José María Granada, tuvo que abandonar el rodaje y la dirección del film por causas desconocidas. No tuvo éxito "Flor de España" y esta mujer, que era actriz y bailarina, nunca más volvió a dirigir una película (Molina, p. 77). 


\section{La primera creadora de la cinematografía española}

De este modo tenemos que el prestigio de ser considerada nuestra primera cineasta corresponde a Rosario $\mathrm{Pi}$, de la que sin embargo se sabe muy poco, se mantiene en un olvido e invisibilidad en la Historia del cine español y sus películas, como señala Josefina Molina, "han sido escasamente analizadas y estimadas". No obstante, de las dos películas de las que conocemos a ciencia cierta su autoría, El Gato Montés (1935) y Molinos de Viento (1938), solo se conserva la primera.

Rosario Pi fue primero productora, ;Yo quiero que me lleven a Hollywood! (Edgar Neville, 1932), y más tarde guionista, Doce hombres y una mujer (Fernando Delgado, 1934). Sin embargo, las películas en las que participó de una u otra manera, a excepción de El Gato Montés, se encuentran desparecidas. Solo tenemos el testimonio de quienes participaron en ellas y la esperanza de que en algún momento, en una colección privada, o perdida en alguna filmoteca, aparezca alguna muestra de estos trabajos.

Si bien es cierto que la figura de Rosario $\mathrm{Pi}$ ha sido sorprendentemente olvidada y no se le ha prestado la atención que tal vez merecía, existen algunos datos que nos permiten hacernos una idea de cómo pudo transcurrir la vida de esta pionera. Sabemos que nació en la Barcelona de finales del siglo XIX, el 29 de julio de 1899. Era la única hija del matrimonio Pi Brujas, aunque su madre, que estaba casada en segundas nupcias, tenía otros hijos de su primer marido. Pi pertenecía a una familia de la burguesía catalana, su padre procedía de una conocida familia de fabricantes de tejidos.

En su infancia, Rosario Pi contrajo la poliomelitis y cuando apenas tenía catorce años ya supo que iba a arrastrar una cojera de por vida. En estos momentos, era tan solo una adolescente cuando tuvo que afrontar la certeza de que no podría caminar o bailar como cualquier otra chica de su edad y que esta contrariedad la acompañaría toda su vida. Sin embargo, lejos de venirse abajo, se convirtió en una mujer fuerte y su cojera nunca le impidió llevar a cabo una vida activa.

Con apenas veinticuatro años, morían sus padres. Ella heredó la casa de sus padres y sus hermanastros se quedaron con la fábrica familiar, dedicada a la producción de tejidos. Rosario Pi montó en la casa un negocio de lencería fina que ella misma importaba o traía de París.

Sabemos también que un tío suyo era distribuidor de películas rusas y alemanas, lo que nos hace pensar que este familiar pudo haber propiciado de alguna manera el primer encuentro de $\mathrm{Pi}$ con el cine. Tal vez fuera este encuentro el que años más tarde la llevó a crear, junto al empresario mexicano 
Emilio Gutiérrez Bringas y al español Pedro Ladrón de Guevara, la Productora Star Films, de la que Rosario Pi figuró como presidenta. Star Films produjo, entre 1931 y 1935, las tres primeras películas sonoras de Edgar Neville, Benito Perojo y Fernando Delgado. Además Rosario Pi dirigió sus dos películas bajo la factoría de su propia productora.

Corría la década de los años 30 y el cine republicano deseaba ser el reflejo de una España nueva, moderna e independiente. Sin embargo, era el glamouroso universo de Hollywood el que seguía seduciendo al público. Rosario Pi aprovechó esta fascinación generalizada y produjo la película ;Yo quiero que me lleven a Hollywood!, de Edgar Neville, una sátira acerca del poder de fascinación que el cine hecho en Estados Unidos tenía en multitud de jóvenes que, en aquel momento, volcaban todos sus sueños en ganar concursos de revistas de belleza o de temática cinematográfica con el anhelo de, así, conseguir marcharse al país norteamericano para triunfar en la meca del cine. La película iYo quiero que me lleven a Hollywood!, como tantas otras, desapareció.

Ese mismo año, la cineasta actuó como asistente de producción en Besos en la nieve (José María Beltrán, 1932), un musical en el que actuaban Carmen Navasqués y Pedro Terol, quien trabajaría más tarde bajo las órdenes de la directora catalana. El film narraba una serie de intrigas amorosas en la estación de esquí del Guadarrama aunque, como pasa con la práctica totalidad de su obra, también se encuentra desaparecido.

Star Films producía, dos años más tarde y bajo la dirección de Fernando Delgado de Lara, Doce hombres y una mujer. La película contaba con la actuación de Irene López de Heredia y narraba la historia de una dama de la alta sociedad que se veía de repente mezclada entre los tejemanejes de una sociedad secreta. Este extraño grupo estaba encabezado por personajes muy influyentes, como un ministro y el jefe de la policía local.

Poco después llegaba El Gato Montés, la primera película de la primera mujer directora de la Historia del cine español. Habría que esperar a los años cincuenta para volver a encontrar nombres de directoras mujeres en nuestro cine. De forma más concreta, los de Margarita Alexandre, que terminó por exiliarse en Cuba, y Ana Mariscal, quien consiguió dirigir once películas entre 1952 y 1968 (Nuño, p. 43).

En su primera película, Rosario Pi adaptó la zarzuela de Penella del mismo nombre, compuesta en 1916, y que había cosechado un gran éxito popular desde el mismo momento de su estreno. Entre las obras de Penella -quien participó en la película de Pi- pueden destacarse, además de El Gato Montés, El padre cura (1908), Corpus Christi (1909), Huelga de señoras (1911) -que concluye que el mejor lugar para la mujer es el cuidado del esposo en su hogar-, La España de pandereta (1914), La última españolada (1917) o El 
milagro de San Cornelio (1927). La mayor parte de sus obras retrataban a "toreros despechados, gitanas casamenteras, curas metomentodos pero de buen corazón, suegras devotas que miran por la decencia de la muchacha joven, etcétera" (Melero, p. 159). Dicho de otro modo, la mayor parte de sus obras -y El Gato Montés no es ninguna excepción- se encuadraban dentro de lo que se llamó entonces "españolada", un género que para Martín-Márquez representaba a España como algo

exótico, un otro primitivo, centrándose de forma metonímica en el subdesarrollo tecnológico, clasista y sexista de Andalucía, la zona [de España] más próxima al Oriente Medio, y presentando un mundo plagado de gitanos [...] cuyas actuaciones de flamenco y corridas de toros les unen visceralmente al terreno de los instintos (Melero, p. 159)

Película y zarzuela narraban la historia de Juanillo y Soleá, dos gitanos enamorados desde la infancia. Un incidente llevaba a Juanillo a la cárcel y Soleá era entonces cortejada por un famoso torero, Rafael el Macareno. Se formaba entonces un extraño triángulo amoroso.

Como apunta Alejandro Melero, en uno de los poquísimos acercamientos que se han hecho a la película de Rosario $\mathrm{Pi}$, la cineasta "mostró especial interés en la reescritura del personaje femenino, Soleá, a la que convirtió en la protagonista de su traslación". Así, en las obras de Penella y Pi asistimos a dos formas totalmente diferentes de retratar al mismo personaje. De esta forma, encontramos que "el texto de Penella presenta un tratamiento que iguala el amor con la posesión, corporal y también material de la persona amada". Por su parte, Justo Romero, en un estudio de la zarzuela de Penella, señalaba que Soleá "presenta los rasgos típicos de la protagonista del drama costumbrista, abnegada, silenciosa e indecisa, insegura y siempre acompañada por la sombra de su madre adoptiva".

Sin embargo, la Soleá de Rosario Pi es una mujer independiente que, no solo no necesita la protección del hombre, sino que es capaz de proteger ella misma a los hombres que la rodean. La nueva Soleá revisitada y escrita por Pi pone fin a la pelea entre los dos hombres primitivos que luchan por su amor sin ni siquiera preguntarle a ella su parecer. La secuencia de la lucha entre los dos pretendientes es tal vez la más reveladora, pues presenta diferencias muy significativas entre las dos versiones. En la de Penella, Soleá no pasa de ser un objeto pasivo que no encuentra, y ni tan siquiera las busca, fuerzas para intervenir en el ritual salvaje de los dos hombres. En la de Pi, ella es el interés mismo de la acción, la que la padece, pero también la que la dirige. Es ella la que ordena a los dos hombres que dejen de pelear, lo cual ellos cumplen escrupulosamente. La mujer interviene en la acción que originalmente había sido exclusivamente masculina -lo mismo que hacía la mujer Rosario Pi al dirigir, por primera vez en la historia de España, una película-, hasta el punto de que Soleá quita el cuchillo de las manos de Juanillo y lo tira al suelo ( $p$. 163). 
En la Soleá cinematográfica se invierten los roles mujer-pasiva, hombre-activo y, con esto, la cineasta "se adelantó varias décadas a lo que iba a ser una de las contribuciones más relevantes del pensamiento y la crítica feminista, interrumpiendo excepcionalmente la línea tradicional que no permitía vías de incursión para personajes femeninos-activos" (p. 163).

Otro incidente violento vuelve a ser el continente de una escena de sumo interés en la obra de $\mathrm{Pi}$, quien introduce una pelea para demostrar la autosuficiencia de su protagonista femenina. La directora sitúa la acción en un bar, en el que un hombre pretende ordenar a Soleá que beba con él e insiste: "te la has de beber [la copa] porque lo mando yo", a lo que sorprendentemente, el personaje creado por la cineasta responde: "en mi cuerpo no manda naide". "Soleá se convierte con estas palabras en uno de los primeros personajes del cine español capaces de mostrar una inquietud por la apropiación y colonización del cuerpo de la mujer en el sistema patriarcal" (p. 170).
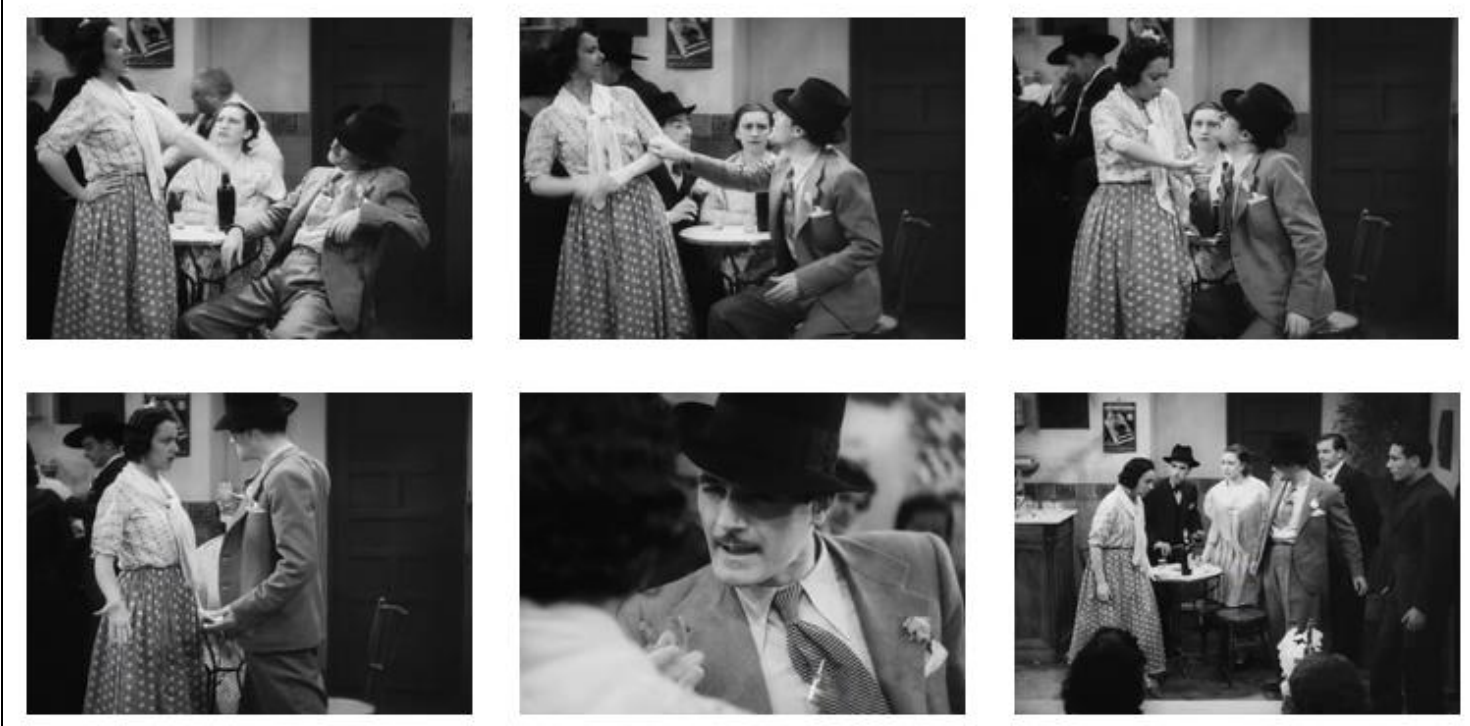

Figuras 1 a 6. Secuencia donde el personaje de Soleá de Rosario Pi se enfrenta a un hombre que pretende obligarla a beber, expresando su autonomía e independencia y alejándose de la aceptación y sumisión ante la violencia machista.

Aún más, la mujer se enfrenta a este hombre -que ha respondido a su contestación "en mi cuerpo no manda naide" usando la violencia físicallamándole "canalla, cobarde, malnacío y mal hombre". Es una mujer que no necesita de un hombre que la defienda. En esta escena, además de la inversión de roles, Rosario Pi también se adelanta introduciendo el tema de abuso físico, del maltrato a la mujer, que todavía tardaría mucho tiempo en instaurarse como tema en la gran pantalla. 
Pero todavía encontraremos una escena más en la que Soleá muestra ser un personaje independiente y autosuficiente. Nos referimos al momento en el que el torero Rafael está cortejando a la gitana $y$, haciendo gala de su caballerosidad, le dice: "¿Dónde vas así, sola por la vida? (...) Eso no pué sé, tú necesitas quien te ampare, quien te defienda". Como no podía ser de otro modo, la Soleá de Pi no acepta estas palabras ni se queda callada. "Ya me defiendo yo", le responde al torero. Rafael insiste: "necesitarás dinero". Y Soleá, lejos de achantarse, vuelve a ponerle en su sitio: "no me hace falta". Es más, se despide del torero diciéndole que, si ella quiere, ya le encontrará. Tenemos aquí otra inversión de roles. En primer lugar, va a ser el personaje masculino el que ahora tenga que esperar por el personaje femenino. No solo esto, además, va a estar a supeditado a la voluntad de la mujer.

Resulta interesante señalar que Soleá no es la única mujer que logrará escapar de los roles tradicionales bajo la narración de la cineasta catalana. Rosario Pi introduce en El gato montés otro personaje femenino -que no estaba en la versión de Penella- y que también se adelantará a su época. Se trata de La Peliculera, una mujer que trabaja en casa de Rafael. La Peliculera, y de ahí su nombre, sueña con triunfar en el mundo del cine y critica el papel que le es asignado a la mujer como ángel del hogar. Nos encontramos ante una mujer que está cansada de fregar y así lo expresa cuando dice: "no puedo con esta vida perra, yo no he nacío para fregar platos". Este personaje también trasgredirá la norma en cuanto a su sexualidad, fantaseando de manera clara y en público con "enredarse" con un francés. En esta escena, y citando a Melero, estamos ante "la única del cine español de la Segunda República en la que una mujer expresa explícitamente su deseo sexual y la autonomía que ella tiene sobre su propio cuerpo sexualizado" (p. 169). Tanto es así que aun protagonizará otra secuencia transgresora. En un momento dado se encuentra con otro empleado de la finca del torero Rafael, que le ha expresado en numerosas ocasiones que siente una atracción por ella. Esta, lejos de mostrarse sumisa ante él, le cuenta que va a ir a ver a unos señores de la industria del cine y que se pondrá ante ellos en prendas menores para que vean su cuerpo y le den un trabajo como actriz en una película. Ella decide sobre su propio cuerpo y sobre a quién y cuándo enseñárselo, actitud cuando menos osada en el cine de la época. 


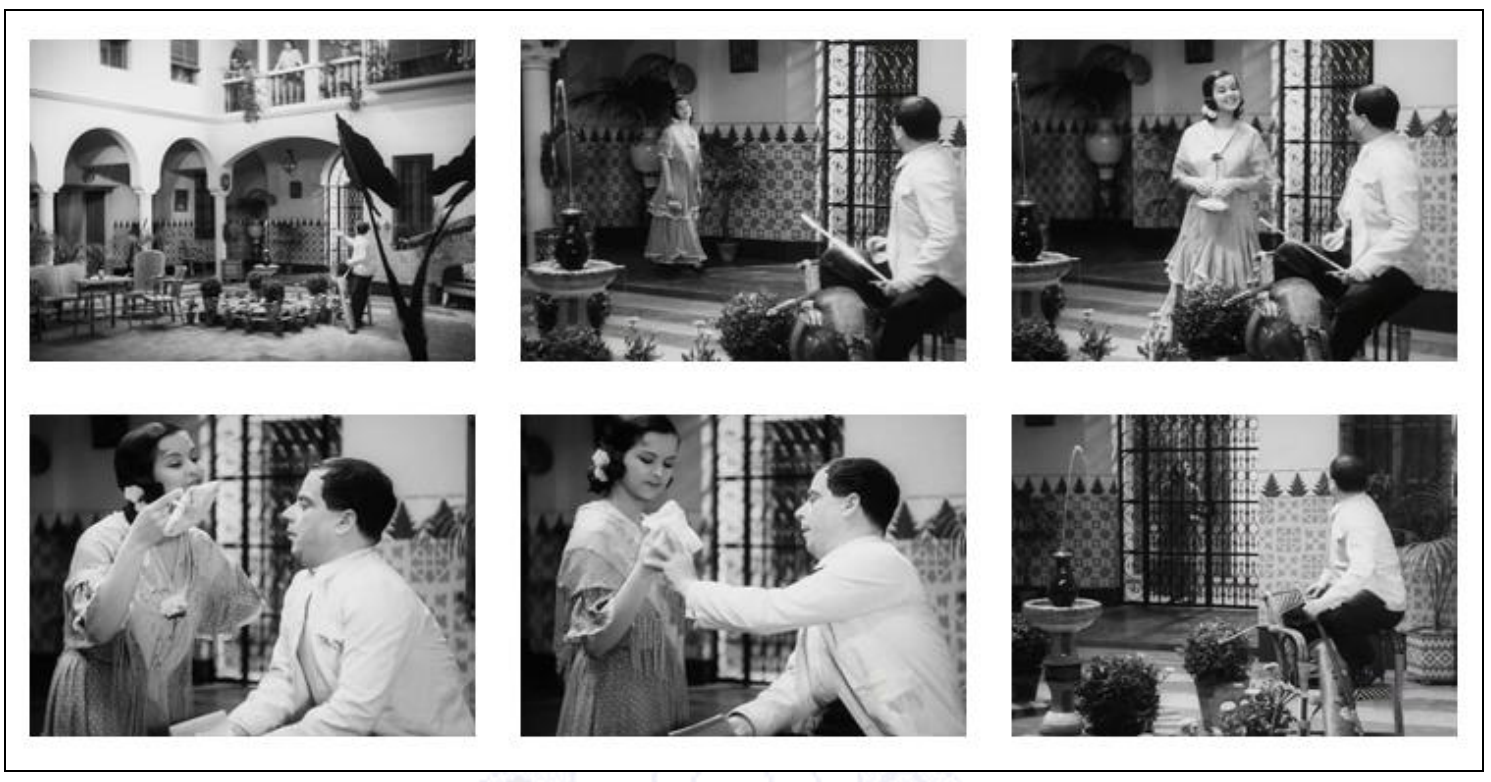

Figuras 7 a 12. Secuencia en la que el personaje de La Peliculera comenta a su compañero de escena que tiene una cita con un director y otras gentes del cine y que se pondrá para ellos un minúsculo traje de baño que lleva en un pequeño paquete, así les mostrará su cuerpo para conseguir un papel en una película.

El gato montés cosechó un éxito considerable en la época (Torres, p. 274), lo que permitió a la cineasta rodar, apenas tres años más tarde y de nuevo con su propia productora, su segunda y última película como directora: Molinos de viento (1938), adaptación de una zarzuela de Ricardo Frutos. Su segunda obra estaba protagonizada por el tenor Pedro Terol y María Mercader, quien tendría una gran importancia en la vida posterior de la directora catalana. Molinos de viento contó con la financiación de un General del ejército, amigo de la madre de María Mercader, y se rodó en plena guerra civil en zona republicana. Esta película, que la actriz, años más tarde, aseguraba no recordaba haber hecho, también desapareció.

El rodaje de Molinos de viento se había "realizado con todos los avances técnicos de la época y producido por CIFESA, la compañía valenciana creada durante la II República y distribuidora de Columbia Pictures" (Camí-Vela, p. 28). Rosario Pi había escogido como localización una Barcelona que asistía, atónita, al comienzo de la guerra civil y a sus constantes bombardeos. En este contexto, Rosario Pi solo pensaba en concluir esta película, de modo que, una vez terminado el rodaje, puso rumbo a París con el negativo para sonorizarla allí, lejos de los peligros de una España en guerra. Una vez en territorio francés, Pi toma la decisión de promocionar a su actriz María Mercader y consigue dos ofertas. Por un lado, la posibilidad de firmar un contrato con la Fox y marchar durante siete años a Nueva York. Por otro, viajar a Roma con una película ya apalabrada. Es entonces cuando la actriz vive una experiencia con la compañía norteamericana que, para una mujer española de los años treinta, debió de resultar traumática. La Fox le había pedido a María Mercader que enseñara las piernas para ver cómo daba su cuerpo en cámara. Esta 
petición, al parecer, resultó desmesurada y del todo indecente a la actriz, que insistió en que el destino elegido fuera, finalmente, Italia.

En Roma, Rosario Pi se dedica sobre todo a traducir guiones al castellano y a ejercer como representante de María Mercader y otras actrices. Mientras tanto, la que fuera la actriz protagonista de Molinos de viento se enamora de Vittorio De Sica. El actor italiano y Rosario $\mathrm{Pi}$ no tardaron en congeniar, pues compartían, además de sentimientos hacia María, edad y aficiones. Los tres se convierten en inseparables y, en plena posguerra española, deciden viajar a Madrid para buscar financiación con la que rodar juntos una película. Sin embargo, esta búsqueda fracasa y no consiguen producir su obra. Tras la frustrada experiencia, los tres amigos regresan a Roma y se separan: el matrimonio De Sica-Mercader continúa dedicado a la cinematografía y Rosario $\mathrm{Pi}$ se dispersa. Se aleja del cine, prueba en otras industrias, empieza a firmar diferentes trabajos como Rizpay y con ese mismo nombre patenta algunos inventos -como un cenicero recreativo o un envase para cerillas-, organiza cenas y espectáculos, y hasta llega a regentar un local nocturno, llamado Jicky Club.

En los años cincuenta, Rosario Pi vuelve a una España que no le dará nunca la oportunidad de volver a hacer cine. Si bien durante la Segunda República había sido mirada con cierta desconfianza por el ambiente intelectual de la época, afín a los valores republicanos, al acusarla de simpatizante del golpe (Marin Silvestre), en la España franquista tampoco encontró una buena acogida. Los valores de la dictadura no encajaban con una mujer independiente, vanguardista, creadora y que ejercía una profesión tradicionalmente masculina. Así, a Rosario Pi, instalada en Madrid y con una situación económica poco boyante, no le queda más remedio que instalarse con una sobrina y aceptar un trabajo en una casa de modas perteneciente al modisto Marbel. En los años sesenta, sin poder haber vuelto a hacer cine, pero manteniendo intacto su espíritu emprendedor, se aventuró a abrir un restaurante de lujo en el Paseo de la Castellana. Sería su última empresa (Zade-Routier).

Rosario Pi murió discreta y plácidamente en 1967. Desde entonces, su figura ha permanecido olvidada e invisible. Cabe preguntarse cómo una mujer que pasa por ser la primera cineasta española, la primera mujer en dirigir cine bajo la factoría de su propia compañía de producción puede seguir, a día de hoy, siendo un personaje desconocido para la inmensa mayoría. Sirva este artículo como un intento de recuperar también la memoria de esas otras víctimas que, si bien no fueron violentamente represaliadas, sí fueron condenadas a un injusto olvido. 


\section{Referencias bibliográficas}

ADÁN, M. A. S. F. (2009). «Mujer, sociedad y costumbres: los felices "Años Veinte", un testimonio singular», Kalakorikos: Revista para el estudio, defensa, protección y divulgación del patrimonio histórico, artístico y cultural de Calahorra y su entorno, (14), 57-80.

ANDERSON, B. S., ZINSSER, J. P., \& Cristóbal, G. N. (1991). Historia de las mujeres: una historia propia (Vol. 1). Barcelona: Crítica.

ANTÓN, J. (6 de enero de 2014). «Marina Ginestà, la joven y desafiante miliciana del fusil». El País. Disponible en:

<http://cultura.elpais.com/cultura/2014/01/06/actualidad/1389047015_066499.ht ml> [Consulta: 16 de abril de 2014]

JIMÉnEZ, P. C. (2006). «Escritoras en la Edad Media». Espéculo: Revista de Estudios Literarios, (33), 56.

Folguera, P., López, M. O., \& Segura, C. (1997). Historia de las mujeres en España. Síntesis.

MARIN SILVESTRE, D. Diccionari Biogràfic de Dones [versión electrónica]. Generalitat de Catalunya i del Govern de les Illes Balears. Disponible en $<$ http://dbd.cat/index.php?option=com_biografies\&view=biografia\&id=5009> [Consulta: 16 de abril de 2014]

Melero, A. (2010). «Apropiación y reapropiación de la voz femenina en la "españolada": el caso de El gato montés". Arenal. Revista de historia de las mujeres, 17 (1), 157-174.

MoLINA, J. (2003). «El cine és el cine de les dones... i dels homes però això ja ho sabem/El cine es el cine de las mujeres... y de los hombres, pero esto ya lo sabíamos. Punto y seguido». DUODA: estudis de la diferència sexual, (24), 7581.

Monterde García, J. C. (2010). «Algunos aspectos sobre el voto femenino en la II República Española: debates parlamentarios». Anuario de la Facultad de Derecho, (28), 261-277.

NuÑo, A. (2001). «Rosario Pi: El gato montés», 1935. La Madriguera, (37), 4243.

ONTAÑón, E. (21 de noviembre de 2002). «En memoria de Aurora Villa, médica y deportista». El País. Disponible en:

<http://elpais.com/diario/2002/11/21/agenda/1037833208_850215.html> [Consulta: 15 de abril de 2014]

Pérez Priego, M. A. (2010). Literatura española medieval (el siglo XV). Madrid: Editorial Universitaria Ramón Areces.

PLAZA, A. P. (2010). «Teatro y compromiso en la obra de Luisa Carnés». Acotaciones: revista de investigación teatral, (25), 91-118.

RomeRo, J. (Ed.) (1992). El gato montés: ópera en tres actos. Sevilla: Cátedra. 
TORRES, A. M. (2004). Directores españoles malditos. Madrid: Huerga y Fierro Editores.

Von Der Walde y M. Reinoso (eds.), (2009). Destiempos: Mujeres en la literatura. Escritoras, 4 (19).

ZADE-RoutieR, S. (1988) ¿Quién es Rosario Pi? [DVD]. España: Amtea.

ZECCHI, B. (2004). «Mujer y cine: estudio panorámico de éxitos y paradojas». En La mujer en la España actual:¿ evolución o involución? (pp. 315-350). Barcelona: Icaria. 